\title{
GABA-Producing Lactococcus lactis Strains Isolated from Camel's Milk as Starters for the Production of GABA-Enriched Cheese
}

\author{
Begoña Redruello ${ }^{1}$, Yasmine Saidi ${ }^{2}\left(\mathbb{D}\right.$, Lorena Sampedro ${ }^{1}\left(\mathbb{D}\right.$, Victor Ladero ${ }^{1,3}{ }^{(\mathbb{D}}$, Beatriz del Rio ${ }^{1,3, *(\mathbb{D})}$ and \\ Miguel A. Alvarez 1,3 (D)
}

1 Dairy Research Institute (IPLA-CSIC), Paseo Rio Linares s/n, 33300 Villaviciosa, Spain; bredruel@ipla.csic.es (B.R.); loresampedro07@gmail.com (L.S.); ladero@ipla.csic.es (V.L.); maag@ipla.csic.es (M.A.A.)

2 Applied Microbiology Laboratory, Department of Biology, Faculty of Nature and Life Sciences, University of Oran, Oran 31000, Algeria; yasmine.saidi@gmail.com

3 Instituto de Investigación Sanitaria del Principado de Asturias (ISPA), Hospital Universitario Central de Asturias, 33006 Oviedo, Spain

* Correspondence: beadelrio@ipla.csic.es; Tel.: +34-985-89-21-31

check for updates

Citation: Redruello, B.; Saidi, Y.; Sampedro, L.; Ladero, V.; del Rio, B.; Alvarez, M.A. GABA-Producing Lactococcus lactis Strains Isolated from Camel's Milk as Starters for the Production of GABA-Enriched Cheese. Foods 2021, 10, 633. https:// doi.org/10.3390/foods10030633

Academic Editors: Paloma López and Maria Teresa Dueñas

Received: 3 March 2021

Accepted: 14 March 2021

Published: 17 March 2021

Publisher's Note: MDPI stays neutral with regard to jurisdictional claims in published maps and institutional affiliations.

Copyright: (c) 2021 by the authors. Licensee MDPI, Basel, Switzerland. This article is an open access article distributed under the terms and conditions of the Creative Commons Attribution (CC BY) license (https:/ / creativecommons.org/licenses/by/ $4.0 /)$.
Abstract: The multiple health benefits attributed to the bioactive compound $\gamma$-aminobutyric acid (GABA) have prompted the food industry to investigate the development of functional GABA-rich foods via the use of GABA-producing microorganisms. This study reports the isolation of six GABAproducing Lactococcus lactis strains from camel's milk; this is the first time that such microorganisms have been isolated from milk. The sequencing and in silico analysis of their genomes, and the characterisation of their technological and safety properties, confirmed their potential as starters. Experimental cheeses made with all six strains (individually) accumulated GABA at concentrations of up to $457 \mathrm{mg} / \mathrm{kg}$. These GABA-producing L. lactis strains could be used as starter cultures for the manufacture of functional GABA-enriched cheeses that provide health benefits to consumers.

Keywords: camel's milk; Lactococcus lactis; GABA; starter cultures; functional cheese

\section{Introduction}

Lactococcus lactis is the lactic acid bacterium (LAB) most widely used as a primary fermentation starter in the dairy industry. It is routinely employed in the production of matured cheese, unripened cheeses (e.g., cream cheeses and cottage cheese), fermented milk products, sour cream, and fermented butter. Based on its traditional usage in the fermentation of food, this species has been granted Qualified Presumption of Safety (QPS) status by the European Food Safety Authority (EFSA, [1]) and it enjoys Generally Regarded as Safe (GRAS) status in the United States [2]. L. lactis plays a major role during the early stages of cheesemaking, since it quickly acidifies milk by metabolizing the lactose present into lactic acid [3]. This lactic acid inhibits the growth of spoilage and pathogenic microorganisms, improving the shelf life and safety of the fermented end product. Some $L$. lactis strains also improve product preservation via the release of antimicrobial substances such as organic acids, $\mathrm{H}_{2} \mathrm{O}_{2}$, and bacteriocins, which inhibit the growth of undesirable (e.g., Clostridium and Bacillus) and pathogenic Gram-positive bacteria (e.g., Staphylococcus aureus and Listeria monocytogenes) [4]. The species also plays a crucial role during cheese ripening via its proteolytic action, which contributes to the formation of compounds involved in the final product's organoleptic properties (flavour, taste, and texture) [3].

Some strains of L. lactis also show interesting probiotic potential. Several studies have shown that certain strains of L. lactis are beneficial to human health via their antiinflammatory [5], immunomodulatory [6], and antioxidant [7] activities. Some strains are 
known to produce $\gamma$-aminobutyric acid (GABA), which can protect against the neurodegeneration induced by injury and help prevent neurological disorders [8]. It also has blood pressure-lowering and anti-diabetic properties, and it exerts an anti-cancer effect through the induction of apoptosis and the inhibition of cancer cell proliferation and the production of metastases. In addition, it is intestine-, hepato-, and cardio-protective, and it has positive effects against anxiety and depression [8]. The fact that GABA has also been approved as a food ingredient in the US and EU have led the pharmaceutical and food industries to show interest in developing functional GABA-based supplements and GABA-enriched foods [8].

No GABA-producing L. lactis strains have ever been isolated from milk. However, dairy products such as fermented milk [9], yoghurt [10], and cheese [11] have been made with GABA-producing LAB isolated from other sources. These products are claimed to have anti-hypertension [9,12] and anti-diabetic effects [10]. GABA-enriched cheeses have been made using adjunct cultures of different GABA-producing LAB species, such as Levilactobacillus brevis [13], Lacticaseibacillus casei [14], Lacticaseibacillus paracasei [15], Lactiplantibacillus plantarum [15], Lentilactobacillus buchneri [16], Streptococcus thermophilus [13], and L. lactis $[12,17,18]$.

GABA is produced by L. lactis via the enzymatic decarboxylation of glutamic acid. The genes involved in this reaction are grouped into the GAD cluster, the transcriptional organization of which was first described in L. lactis MG1363 by Sanders et al. [19]. The GAD cluster of L. lactis consists of three genes: gadR, which codes for a positive transcriptional regulator (GadR), gadC, which lies downstream and codes for the glutamate-GABA antiporter (GadC), and finally gadB, which codes for glutamate decarboxylase (GadB; the enzyme that catalyzes the decarboxylation of glutamate to GABA). The GAD pathway contributes to the acid resistance shown by L. lactis in acidic environments [19], which is a property seen in other LAB such as Limosilactobacillus reuteri [20] and indeed other types of bacteria such as Escherichia coli and Listeria monocytogenes [21].

The concentration of GABA in camel's milk is high, certainly far more so than in cow's and human milk [22], suggesting it could be a source of GABA-producing L. lactis strains that might have applications in the dairy industry. The objectives of the present work were to isolate GABA-producing L. lactis strains from raw camel's milk and to perform the characterization of their genomic, technological, and safety properties. Finally, the potential of these strains as starter cultures for the production of functional GABA-enriched cheeses was assessed.

\section{Materials and Methods}

\subsection{Bacterial Strains and Growth Conditions}

Table 1 lists the bacterial strains used in this study. L. lactis cultures were grown in De Man, Rogosa and Sharpe (MRS) or M17 broth (Oxoid, Basingstoke, UK) supplemented with $0.5 \%(w / v)$ glucose (GM17) at $30{ }^{\circ} \mathrm{C}$ without aeration. Streptococcus thermophilus strains were grown in M17 broth supplemented with $0.5 \%(w / v)$ lactose and incubated at $42{ }^{\circ} \mathrm{C}$ without aeration. Latilacctobacillus sakei was grown in MRS at $30^{\circ} \mathrm{C}$ without aeration. Listeria innocua was grown in Tryptic Soy Broth (TSB) broth (Oxoid) at $37^{\circ} \mathrm{C}$ without aeration. Micrococcus luteus was grown in TSB broth at $37^{\circ} \mathrm{C}$ with shaking.

\subsection{Milk Sample Collection}

Twelve milk samples were obtained directly from the udder of lactating camels that came from eight different areas of Algeria (Abadla, Adrar, Bechar, Ghardaia, Mecheria, Oran, Saida, and Tindouf) between October 2015 and October 2017. Samples were kept at $4{ }^{\circ} \mathrm{C}$ until processed. 
Table 1. Microorganisms used in this study.

\begin{tabular}{|c|c|c|}
\hline Strains/Isolates & Relevant Features & Reference/Source \\
\hline \multicolumn{3}{|l|}{ Bacterial strains } \\
\hline Latilactobacillus sakei CECT $906^{\mathrm{T}}$ & Microbial indicator for bacteriocin production & CECT $^{\mathrm{a}}$ \\
\hline Lactococcus lactis subsp. cremoris MG1363 & Microbial indicator for bacteriocin production & [23] \\
\hline Lactococcus lactis NCDO $604^{\mathrm{T}}$ & Positive control for proteolytic activity & $\mathrm{NCDO}^{\mathrm{b}}$ \\
\hline Lactococcus lactis SH4109 & Positive control for proteolytic activity & [23] \\
\hline Listeria innocua CECT $910^{\mathrm{T}}$ & Microbial indicator for bacteriocin production & CECT $^{a}$ \\
\hline Micrococcus luteus NCIMB 8166 & Microbial indicator for bacteriocin production & $\mathrm{NCIMB}^{\mathrm{c}}$ \\
\hline Streptococcus thermophilus CNRZ 1066 & Microbial indicator for bacteriocin production & $\mathrm{CNRZ}^{\mathrm{d}}$ \\
\hline Streptococcus thermophilus LMD9 & Microbial indicator for bacteriocin production & $\mathrm{NBCC}^{\mathrm{e}}$ \\
\hline Lactococcus lactis subsp. cremoris SK11 & Non-GABA producer starter culture & [24] \\
\hline \multicolumn{3}{|l|}{ Mold strain } \\
\hline Penicillium roqueforti $1 \mathrm{AM} 8$ & Proteolytic mold from Cabrales cheese & [25] \\
\hline \multicolumn{3}{|l|}{ Lactococcus lactis isolates } \\
\hline L. lactis subsp. lactis LEY6 & GABA producer & This work \\
\hline L. lactis subsp. lactis LEY7 & GABA producer & This work \\
\hline L. lactis subsp. lactis LEY8 & GABA producer & This work \\
\hline L. lactis subsp. lactis LEY11 & GABA producer & This work \\
\hline L. lactis subsp. lactis LEY12 & GABA producer & This work \\
\hline L. lactis subsp. lactis LEY13 & GABA producer & This work \\
\hline
\end{tabular}

${ }^{a}$ CECT: Spanish Type Culture Collection, Spain. ${ }^{b}$ NCDO: National Collection of Dairy Organisms, now part of the NCIMB. ${ }^{c}$ NCIMB: National Collection of Industrial, Food and Marine Bacteria, UK. ${ }^{d}$ CNRZ: Centre National de Recherches Zootechniques, France. ${ }^{e}$ NBCC: National Bureau Collection Corporation NCCB, US. ${ }^{\mathrm{T}}$ Type strain.

\subsection{Isolation of Lactic Acid Bacteria and Phenotypic Characterization}

To first isolate LAB species, serial dilutions of camel's milk were plated in duplicate on GM17 agar and incubated at $30^{\circ} \mathrm{C}$. Then, those isolates were subjected to Gram staining and catalase activity [26] and spore formation analyses [27]; those that met the appropriate criteria were identified as LAB.

To identify Lactococcus species among these LAB, cell morphology was examined by optical microscopy. Isolates were also grown in GM17 broth at $30{ }^{\circ} \mathrm{C}$ and $45^{\circ} \mathrm{C}$, in the presence of $4 \%$ and $6.5 \% \mathrm{NaCl}$, adjusted to $\mathrm{pH} 9.6$, with inverted Durham tubes to determine $\mathrm{CO}_{2}$ production from glucose. Those ovococci able to grow at $45^{\circ} \mathrm{C}$, at $\mathrm{pH} 9.6$, and in the presence of $6.5 \% \mathrm{NaCl}$ were assigned to Enterococcus, while those able to resist $\mathrm{pH} 9.6$, and / or a temperature of $45^{\circ} \mathrm{C}$, but not the presence of $6.5 \% \mathrm{NaCl}$, were assigned to Lactococcus [28].

Then, Lactococcus isolates were grown in M16BCP medium (containing $2 \mathrm{mg} / \mathrm{mL}$ lactose, $4 \mathrm{mg} / \mathrm{mL}$ arginine, with bromocresol purple as a $\mathrm{pH}$ indicator) to confirm their capacity to hydrolyze arginine via the action of arginine dihydrolase (ADH) [also known as arginine deiminase (ADI)].

\subsection{Molecular Identification of Lactococcus Isolates}

The Lactococcus isolates were identified at the species level by $16 S$ rRNA gene sequencing following the protocol described in Saidi et al. [29].

\subsection{Identification of GABA-Producing Lactococcus in Culture Media}

GABA production was detected in supernatants obtained after 5 days of incubation in $1 \mathrm{~mL}$ of GM17 broth supplemented with $5 \mathrm{mM}$ L-glutamic acid monosodium salt monohydrate (monosodium glutamate) (Sigma-Aldrich, Madrid, Spain). Culture supernatants were derivatized with diethyl ethoxymethylenemalonate (Sigma-Aldrich, Munich, Germany) and subjected to ultra-high performance liquid chromatography (UHPLC) using a Waters H-Class ACQUITY UPLC apparatus with a UV detector (Waters, Milford, MA, USA), following the procedures described by Redruello et al. [30]. 


\subsection{Whole-Genome Sequencing and Bioinformatic Analyses}

Total DNA from L. lactis isolates was isolated from $1.5 \mathrm{~mL}$ of an overnight culture. Cell pellets were collected by centrifugation and washed with $1 \mathrm{~mL}$ of PBS. Then, the cells were resuspended in a lysis buffer containing $20 \mathrm{mg} / \mathrm{mL}$ lysozyme (Merck, Madrid, Spain), 200 U mutanolysin (Sigma-Aldrich), $2 \mathrm{mg} / \mathrm{mL}$ RNase (AppliChem, Darmstadt, Germany), $20 \mathrm{mM}$ Tris- $\mathrm{HCl}$ (pH 8.0), $2 \mathrm{mM}$ EthyleneDiamineTetraAcetic acid (EDTA), and 1.2\% Triton X-100 (Merck). Then, this lysis suspension was incubated at $37^{\circ} \mathrm{C}$ for $1 \mathrm{~h}$ and DNA extracted using the DNeasy Blood and Tissue Kit (Qiagen, Hilden, Germany) according to the manufacturer's instructions. DNA was stored at $4{ }^{\circ} \mathrm{C}$ until analysis. A $0.5 \mathrm{kbp}$ genomic library was constructed and subjected to $150 \mathrm{bp}$ paired-end sequencing (providing approximately 25 -fold coverage) using a HiSeq 1000 system sequencer (Illumina, San Diego, CA, USA) (performed at GATC [Eurofins Genomics, Ebersberg bei München, Germany]). Quality filtered reads were assembled using SPAdes software v.3.13.0. Annotation was performed using the Prokaryotic Genomes Annotation Pipeline (PGAP) [31] on the NCBI server, improving the results obtained in BLAST analyses [32]. Gene clusters involved in technologically relevant features were identified by blast comparison. Bacteriocin clusters were analyzed with BAGEL 4 software [33]. The genome sequences of six GABA-producing L. lactis strains-here denominated LEY6, LEY7, LEY8, LEY11, LEY12, and LEY13-were deposited with BioProject PRJNA596610 in the NCBI BioProject database (http: / / www.ncbi. nlm.nih.gov / bioproject/596610, accessed on 27 January 2021) under the accession numbers SAMN13634154, SAMN13634584, SAMN13634590, SAMN13634615, SAMN13634616, and SAMN13634617 respectively. A comparative analysis of the genes present in the genomes of these six strains (core and accessory genome) was performed using Roary v.3.11.2 software [34]. The generated cluster tree was visualized with Phandango v.1.3.0 [35].

\subsection{Acidifying Capacity}

Ultra-high temperature (UHT) skimmed cow's milk were inoculated with overnight cultures of the six GABA-producing L. lactis strains $\left(1 \%(v / v), 10^{7} \mathrm{cfu} / \mathrm{mL}\right)$ and incubated at $30^{\circ} \mathrm{C}$ for $18 \mathrm{~h}$. The $\mathrm{pH}$ values were recorded after 6 and $18 \mathrm{~h}$ of incubation, and milk clotting was assessed at the end of fermentation. The experiment was performed in triplicate.

\subsection{Proteolytic Activity}

The proteolytic activity of the GABA-producing L. lactis strains was examined by a qualitative method on Plate Count Agar (PCA) (Oxoid) supplemented with 2\% UHT skimmed cow's milk as described by Saidi et al. [29]. In addition, proteolytic activity was quantitatively determined using the O-phthaldialdehyde (OPA) method following the protocol described by the same author. Positive controls involved L. lactis strains known for their good proteolytic activity (i.e., L. lactis NCDO $604^{\mathrm{T}}$ and L. lactis SH4109 [Table 1]). Negative controls (non-inoculated UHT skimmed milk samples incubated under the same conditions) were run in parallel.

\subsection{Dextran Production}

Dextran production was determined using Mayeux, Sandine and Elliker (MSE) agar medium rich in sucrose as described in Saidi et al. [29].

\subsection{Production of Volatile Compounds}

To determine the production of volatile compounds, UHT skimmed cow's milk was inoculated with individual overnight cultures of the GABA-producing L. lactis strains at $1 \%(v / v)$ and incubated for $24 \mathrm{~h}$ at $30^{\circ} \mathrm{C}$. A head space gas chromatograph (Agilent Technologies, Wilmington, DE, USA) connected to a mass spectrophotometer detector (HS/GC/MS) was used to quantify volatile compounds [29]. They were quantified as the normalized value of their chromatogram peak area using cyclohexanone $(3.6 \mu \mathrm{g} / \mathrm{mL})$ as an internal standard, which was given a value of 100. Negative controls (non-inoculated UHT skimmed cow's milk samples) were performed in parallel. 


\subsection{Production of Antimicrobial Substances}

To determine the antimicrobial activity of the isolates, well-diffusion assays were performed according to Saidi et al. [29]. The strains used as microbial indicators are listed in Table 1 . The antimicrobial activity of microbially secreted molecules was assessed by measuring the zone of inhibition (including the well diameter) that appeared after $24 \mathrm{~h}$ of incubation.

\subsection{Production of Biogenic Amines}

The production of the biogenic amines (BA) tyramine, histamine, putrescine, and cadaverine from their respective precursor amino acids (tyrosine, histidine, agmatine, ornithine, and lysine) was assessed as described by Saidi et al. [29] with minor modifications (GM17 broth, instead of MRS, was supplemented with $1 \mathrm{mM}$ of the corresponding amino acid substrate). The accumulation of BA in the supernatant of cell cultures was quantified as described in Section 2.5.

\subsection{In Silico Prediction of Antimicrobial Resistance Genes}

The draft genome sequences of the L. lactis strains were screened for the presence of antimicrobial resistance genes using ResFinder v.3.2 software [36] and Resistance Gene Identifier software (RGI v.5.1.0) [37]. The RGI criteria used in the analysis were perfect, strict, complete genes only, and high quality/coverage.

\subsection{Experimental Cabrales-Like Mini Cheeses}

The six L. lactis strains described in Table 1 were used individually as starter strains to produce experimental Cabrales-like mini cheeses. Overnight cultures of L. lactis isolates $\left(10^{6} \mathrm{cfu} / \mathrm{mL}\right)$ were individually inoculated into sterilized bottles containing $200 \mathrm{~mL}$ of commercial UHT cow's milk; the mold Penicillium roqueforti $1 \mathrm{AM} 8\left(10^{3} \mathrm{cfu} / \mathrm{mL}\right)$ and $\mathrm{CaCl}_{2}$ $(0.02 \% w / v)$ was also added to the bottles. Then, the mixtures were left at $30{ }^{\circ} \mathrm{C}$ for $2 \mathrm{~h}$ to initiate the growth of the cultures. After this time, liquid rennet extract of bovine and ovine (lamb) origin (Nievi, Vizcaya, Spain) was added as indicated by the manufacturer. The bottles were inverted three times and left to coagulate at $30^{\circ} \mathrm{C}$ until the curd acquired the appropriate consistency; then, it was cut, and the bottles were inverted for $20 \mathrm{~min}$ to promote draining before centrifugation at $220 \times \mathrm{g}$ for $10 \mathrm{~min}$ at room temperature to remove all the whey. All steps were performed under sterile conditions. The mini-cheeses produced were kept in closed, screw-capped sterile jars in a ripening chamber at $15^{\circ} \mathrm{C}$ for 90 days. Then, one sample from each mini cheese was obtained, and their GABA, glutamic acid, tyramine, histamine, putrescine, cadaverine, and agmatine contents were determined by UHPLC as described by del Rio et al. [25].

\subsection{Statistical Analysis}

A Student $t$-test was performed for mean comparison between two groups. Mean comparison among three or more groups was conducted via one-way analysis of variance (ANOVA) test followed by a pairwise comparison Tukey post-hoc test. Significance was set at $p<0.05$. Statistical analysis was carried out using the open source R software (v. 3.5.3) (https:/ / www.r-project.org/, accessed on 27 January 2021).

\section{Results}

\subsection{Phenotypic Characterization and Molecular Identification of LAB Isolates}

Fourteen isolates that were Gram-positive, catalase negative, and non-spore-forming, and thus considered to be LAB, were initially selected. The morphology of their cells, as observed by optical microscopy, indicated 12 isolates $(86 \%)$ to be ovococci and two (14\%) to be bacilli. The ovococci were phenotypically characterized (Table 2). All the isolates were able to hydrolyze arginine; none produced $\mathrm{CO}_{2}$ and were therefore considered homofermentative. Six of these ovococci were able to grow at $45^{\circ} \mathrm{C}, \mathrm{pH} 9.6$, and in the presence of $6.5 \% \mathrm{NaCl}$, suggesting they belonged to the genus Enterococcus (data not shown). 
Table 2. Phenotypic characterization of L. lactis isolates from Algerian camel's milk.

\begin{tabular}{cccccc}
\hline \multirow{2}{*}{$\begin{array}{c}\text { Lactococcus Milk } \\
\text { Isolates }\end{array}$} & \multirow{2}{*}{$\begin{array}{c}\text { Geographic Location of } \\
\text { Milk Samples }\end{array}$} & \multicolumn{5}{c}{ Growth at } \\
\cline { 3 - 6 } & Saida & $\mathbf{4 5}{ }^{\circ} \mathbf{C}$ & $\mathbf{p H ~ 9 . 6}$ & $\mathbf{4 \% ~ N a C l}$ & $\mathbf{6 . 5 \% ~ N a C l}$ \\
\hline LEY6 & Saida & + & + & + & - \\
LEY7 & Saida & - & + & + & - \\
LEY8 & Bechar & + & + & + & - \\
LEY11 & Ghardaia & + & + & + & - \\
LEY12 & Tindouf & + & - & + & - \\
LEY13 & & & + & + & - \\
\hline
\end{tabular}

- Negative; + Positive.

The other six were able to resist $\mathrm{pH} 9.6$, and / or a temperature of $45^{\circ} \mathrm{C}$, but they did not grow in the presence of $6.5 \% \mathrm{NaCl}$. These latter strains were assigned to the genus Lactococcus, since it has been reported that some L. lactis strains isolated from camel's milk are thermotolerant (resist up to $50^{\circ} \mathrm{C}$ ) and/or are able to grow at $\mathrm{pH} 9.6$ [28]. $16 \mathrm{~S} r \mathrm{RNA}$ gene sequencing confirmed that all six to belong to Lactococcus lactis subsp. lactis; they were named L. lactis LEY6, L. lactis LEY7, L. lactis LEY8, L. lactis LEY11, L. lactis LEY12, and L. lactis LEY13 (Table 1) (hereafter LEY6, LEY7, LEY8, LEY11, LEY12, and LEY13). These strains came from milk samples obtained from different geographical locations; LEY6, LEY7, and LEY8 were in milk from the region of Saida, LEY11 was in milk from Bechar, LEY12 was in milk from Ghardaia, and LEY13 was in milk from Tindouf (Table 2).

\subsection{All six L. lactis Isolates Produced GABA in Culture Media}

All six selected L. lactis isolates produced GABA (Figure 1). LEY6, LEY7, and LEY8 produced significantly greater amounts (from $1.74 \pm 0.08 \mathrm{mM}$ for LEY6, to $1.80 \pm 0.10 \mathrm{mM}$ for LEY7) than did LEY11, LEY12, and LEY13 (ranging from $1.22 \pm 0.05 \mathrm{mM}$ for LEY13, to $1.32 \pm 0.09 \mathrm{mM}$ for LEY12). No significant differences were seen between the amount of GABA produced by LEY6, LEY7, and LEY8, nor between LEY11, LEY12, and LEY13.

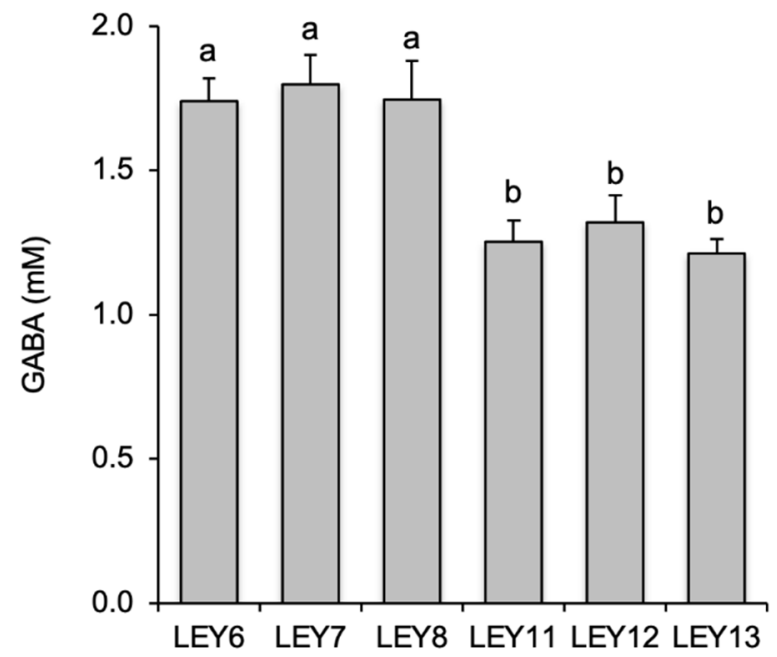

Figure 1. Production of $\gamma$-aminobutyric acid (GABA) by L. lactis isolates grown in GM17 supplemented with $5 \mathrm{mM}$ of monosodium glutamate for 5 days. Supernatants were analyzed by ultra-high performance liquid chromatography (UHPLC) to determine the GABA concentration of the extracellular medium. Bars with different letters indicate significant differences $(p<0.05)$.

3.3. Whole-Genome Sequencing and Comparison Confirmed the Six GABA-Producing L. lactis to Be Different Strains

Table S1 shows the general genomic information obtained for the six GABA-producing L. lactis isolates. Whole-genome assembly revealed draft genome sizes of between 2,513,704 and $2,872,551 \mathrm{bp}$. After pangenome analysis, a total of 3754 genes were identified. The 
core genome was composed of 1982 genes. The isolates showed a variable number of unique genes ranging from 7 in LEY13 up to 98 in LEY6. The other 1772 genes were shared between two or more isolates. These results indicate that the six GABA-producing L. lactis isolates are different strains. A cluster tree based on the pangenome results was constructed (Figure 2) and revealed the existence of two major groups, one including strains LEY6, LEY7, and LEY8 and the other including LEY11, LEY12, and LEY13.
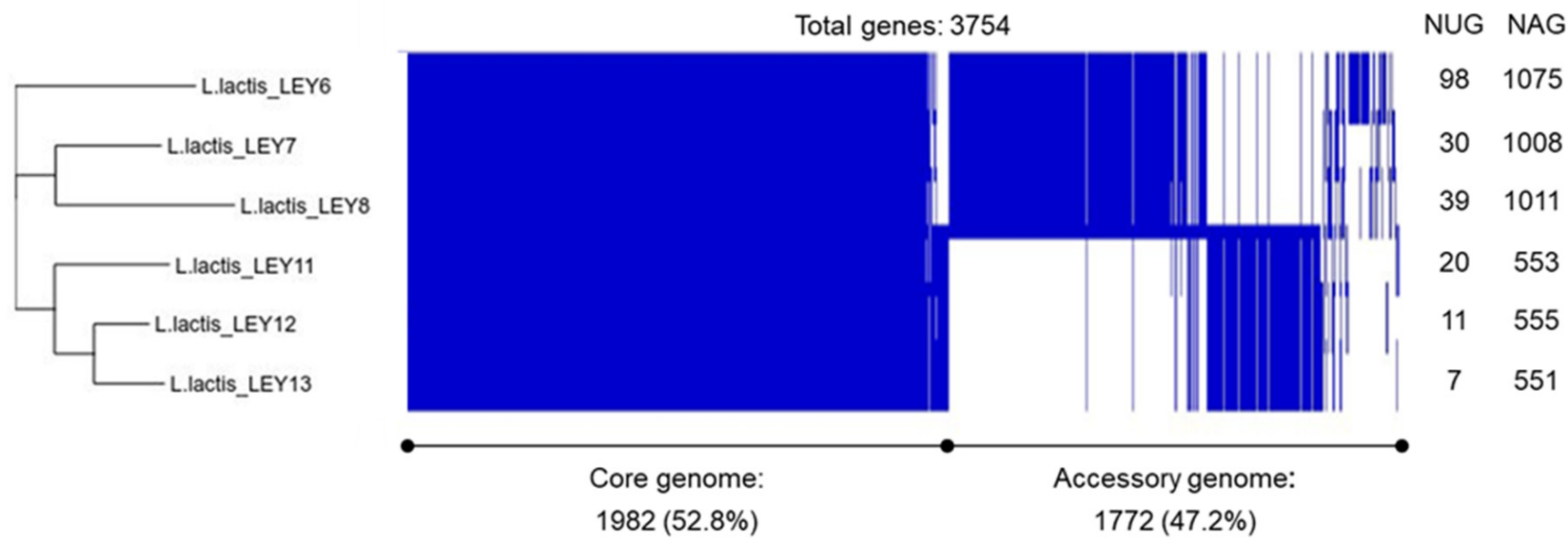

Figure 2. Pangenome analysis of the six GABA-producing L. lactis isolates as determined using Roary software. The cluster tree based on 3754 single genes was produced using Phandango software. The number of unique genes (NUG) and accessory genes (NAG) are shown on the right.

\subsection{In Silico Identification of the GAD Cluster and Other Technologically Relevant Genes in the Genome of the GABA-Producing L. lactis Strains}

The GAD gene cluster involved in GABA production was identified in all six strains (Table S2). The genetic organization of this cluster was identical to that previously described in the GABA non-producer L. lactis subsp. cremoris MG1363 [19]. All six GABA-producing strains had gene clusters involved in the ability to grow in milk, e.g., the lactose phosphotransferase operon (lacR-lacABCDFEGX), the genes encoding cell wall-associated proteases ( $p r t P$ and prtM), and those coding for the oligopeptide permease system (oppDFBCA) (Table S2). They also had putative genes for a citrate/sodium symporter and a malolactic enzyme that might be involved in citrate utilization (Table S2). LEY6, LEY7, and LEY8 had a putative locus for a cluster coding for a bacteriocin similar to macedovicin (annotated as type A2 lantipeptide), while LEY11, LEY12, and LEY13 had another two, one for a bacteriocin similar to carnolysin (annotated as type 2 lantibiotic) and one for another similar to Nisin Z (annotated as a gallidermin/nisin family lantibiotic) (Table S2).

\subsection{Technological Characterization of the GABA-Producing L. lactis Strains 3.5.1. Acidifying Capacity}

The six L. lactis strains were able to acidify the milk, with no differences among them, either after $6 \mathrm{~h}$ or after $18 \mathrm{~h}$ of incubation $(p<0.05)$; all reduced the $\mathrm{pH}$ by more than 1 unit (between 1.06 for LEY12 and 1.65 for LEY6) in the first $6 \mathrm{~h}$. A significative reduction in the $\mathrm{pH}$ value was found after $18 \mathrm{~h}$ for all the strains $(p<0.05)$, from $4.12 \pm 0.03$ for LEY13 to $4.32 \pm 0.31$ for LEY7 (Table 3). All the strains completely clotted the milk after $18 \mathrm{~h}$ of incubation (Table 3). 
Table 3. Acidification kinetics of the L. lactis isolates.

\begin{tabular}{cccc}
\hline \multirow{2}{*}{ L. lactis Isolates } & \multicolumn{3}{c}{ Incubation in UHT Skimmed Milk * } \\
\cline { 2 - 4 } & $\mathbf{p H}$ after $\mathbf{6 ~ h}$ & pH after $\mathbf{1 8 ~ h}$ & Milk Clotting after $\mathbf{~ 1 8 ~ h}$ \\
\hline LEY6 & $5.12 \pm 0.26^{\mathrm{a}, \mathrm{a}}$ & $4.21 \pm 0.13^{\mathrm{a}, \mathrm{b}}$ & + \\
LEY7 & $5.33 \pm 0.54^{\mathrm{a}, \mathrm{a}}$ & $4.32 \pm 0.31^{\mathrm{a}, \mathrm{b}}$ & + \\
LEY8 & $5.14 \pm 0.31^{\mathrm{a}, \mathrm{a}}$ & $4.14 \pm 0.07^{\mathrm{a}, \mathrm{b}}$ & + \\
LEY11 & $5.63 \pm 0.33^{\mathrm{a}, \mathrm{a}}$ & $4.22 \pm 0.12^{\mathrm{a}, \mathrm{b}}$ & + \\
LEY12 & $5.71 \pm 0.50^{\mathrm{a}, \mathrm{a}}$ & $4.18 \pm 0.09^{\mathrm{a}, \mathrm{b}}$ & + \\
LEY13 & $5.42 \pm 0.13^{\mathrm{a}, \mathrm{a}}$ & $4.12 \pm 0.03^{\mathrm{a}, \mathrm{b}}$ & + \\
\hline
\end{tabular}

${ }^{*} \mathrm{pH}$ of non-inoculated UHT skimmed milk: 6.77; Values represent the mean \pm standard deviation from three independent experiments; the first superscript letter indicates mean comparison among strains for each analyzed time period, while the second superscript letter indicates mean comparison between time periods for each strain; same letter indicates no significant differences $(p<0.05) ;+$ Total clotting of milk.

\subsubsection{Proteolytic Activity}

All six strains showed a similar proteolytic activity, producing $1.177 \pm 0.05 \mathrm{mM}$ Gly for LEY8 to $1.364 \pm 0.20 \mathrm{mM}$ Gly for LEY12 (Figure 3).

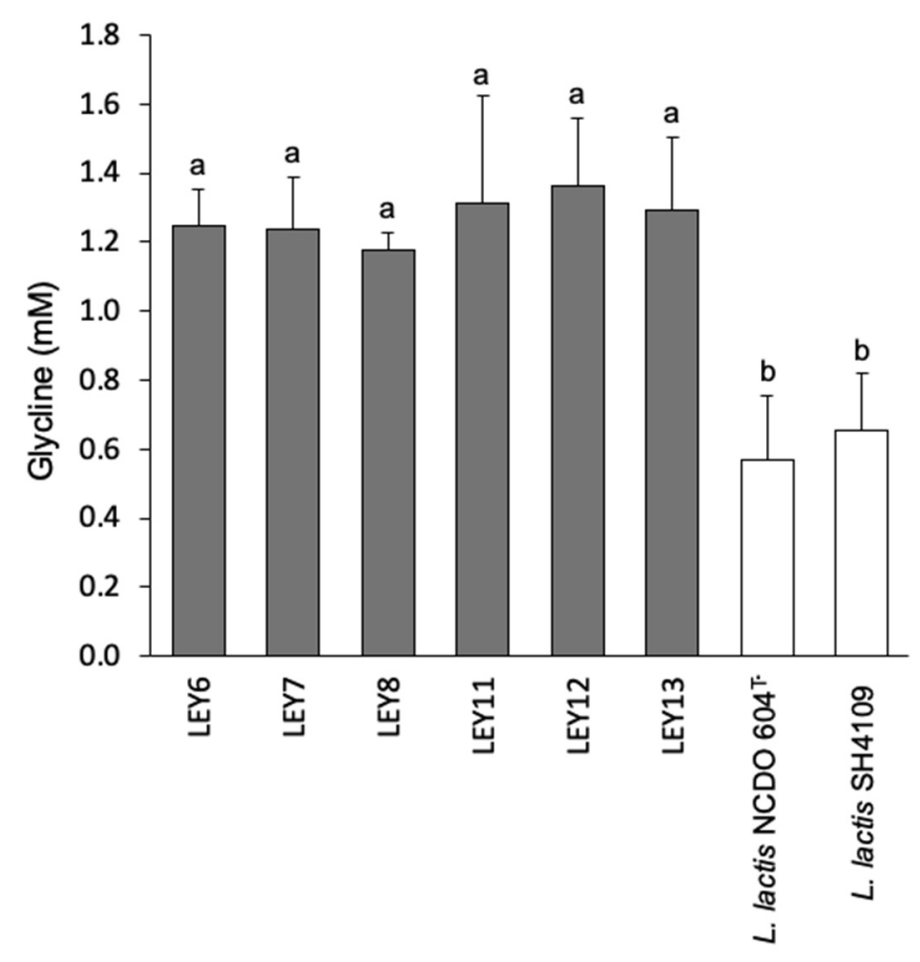

Figure 3. Proteolytic activity of the GABA-producing L. lactis strains as determined by the Ophthaldialdehyde (OPA) assay. Proteolytic activity was recorded as millimoles of glycine released after incubation in skimmed cow's milk at $30{ }^{\circ} \mathrm{C}$ for $24 \mathrm{~h}$, using a glycine calibration curve. The strains used as positive control were L. lactis NCDO $604^{\mathrm{T}}$ and L. lactis SH4109. Bars with different letters indicate significant differences $(p<0.05)$.

In addition, all six strains showed significantly stronger proteolytic activity than $L$. lactis NCDO $604^{\mathrm{T}}$ and L. lactis SH4109 $(p<0.05)$ (positive controls). The slight differences observed among the six L. lactis strains were not statistically significant.

\subsubsection{Dextran Production}

None of the L. lactis strains produced dextran. 


\subsubsection{Production of Volatile Compounds}

Table 4 shows the 12 major volatile compounds produce by the six GABA-producing strains. All the strains produced acetaldehyde, 2-methyl propanal, 3-methyl butanal, ethanol, 2-methyl-1-propanol, and 2 or 3-methyl-1-butanol. LEY6 and LEY7 produced the highest amount of 2-methyl-1-propanol and (plus LEY8) of 2 or 3-methyl-1-butanol $(p<0.05)$. No mean differences for the rest of the common compounds were found among the strains. 2-Methyl-butanal was only found, in a similar amount, in LEY6, LEY7, and LEY8 while methyl acetate and acetic acid were found only in LEY11, LEY12, and LEY13. Four strains (LEY7, LEY8, LEY12, and LEY13) produced 2,2,4,6,6 PMH, while only two (LEY11 and LEY12) produced methyl butanoate. Only LEY12 produced acetoin, although in negligible amounts. Strains LEY11 and LEY12 produced the largest number of volatile compounds (10 and 12 respectively).

Table 4. Volatile compounds produced by the L. lactis isolates during growth at $30^{\circ} \mathrm{C}$ for $24 \mathrm{~h}$ in ultra-high temperature (UHT) skimmed milk (HS/GC/MS analysis). Values represent the mean \pm the standard deviation of three independent experiments.

\begin{tabular}{|c|c|c|c|c|c|c|}
\hline \multirow[b]{2}{*}{ Volatile Compound ${ }^{\dagger}$} & \multicolumn{6}{|c|}{ Strains } \\
\hline & LEY6 & LEY7 & LEY8 & LEY11 & LEY12 & LEY13 \\
\hline Acetaldehyde & $76.9 \pm 7.5^{a}$ & $25.7 \pm 44.5^{\mathrm{a}}$ & $57.7 \pm 52.4^{a}$ & $23.9 \pm 4.3^{a}$ & $21.9 \pm 3.6^{a}$ & $26.2 \pm 8.6^{\mathrm{a}}$ \\
\hline 2-Methyl propanal & $179.1 \pm 15.5^{\mathrm{a}}$ & $123.5 \pm 43.2^{\mathrm{a}}$ & $180.0 \pm 35.3^{\mathrm{a}}$ & $121.3 \pm 22.3^{\mathrm{a}}$ & $99.8 \pm 30.9^{a}$ & $131.8 \pm 21.9^{\mathrm{a}}$ \\
\hline Methyl acetate & $-\mathrm{b}$ & $-\mathrm{b}$ & $-\mathrm{b}$ & $26.1 \pm 7.5^{\mathrm{a}}$ & $25.2 \pm 9.4^{\mathrm{a}}$ & $26.9 \pm 2.3^{a}$ \\
\hline 2-Methyl butanal & $72.6 \pm 12.9^{\mathrm{a}}$ & $80.1 \pm 10.6^{a}$ & $61.8 \pm 16.9^{a}$ & $-\mathrm{b}$ & $-b$ & $-b$ \\
\hline 3-Methyl butanal & $877.7 \pm 70.3^{a}$ & $796.1 \pm 197.7^{a}$ & $797.0 \pm 50.3^{\mathrm{a}}$ & $852.8 \pm 244.5^{\mathrm{a}}$ & $588.8 \pm 248.1^{\mathrm{a}}$ & $897.9 \pm 154.6^{a}$ \\
\hline Ethanol & $396.5 \pm 32.5^{\mathrm{a}}$ & $353.5 \pm 107.6^{\mathrm{a}}$ & $340.5 \pm 18.8^{\mathrm{a}}$ & $351.5 \pm 59.8^{\mathrm{a}}$ & $315.3 \pm 32.7^{a}$ & $362.6 \pm 58.5^{a}$ \\
\hline $2,2,4,6,6 \mathrm{PMH} \ddagger$ & $-\mathrm{b}$ & $95.0 \pm 164.6^{\mathrm{a}}$ & $66.4 \pm 115.1^{\mathrm{a}}$ & $-b$ & $51.1 \pm 88.5^{\mathrm{a}}$ & $83.6 \pm 144.9^{\mathrm{a}}$ \\
\hline Methyl butanoate & $-b$ & $-\mathrm{b}$ & $-\mathrm{b}$ & $2.3 \pm 4.0^{\mathrm{a}}$ & $9.1 \pm 8.0^{\mathrm{a}}$ & $-\mathrm{b}$ \\
\hline 2-Methyl-1-propanol & $55.6 \pm 2.2^{\mathrm{a}}$ & $51.4 \pm 48.6^{\mathrm{a}}$ & $41.4 \pm 7.6^{b}$ & $30.7 \pm 1.8^{b}$ & $35.7 \pm 6.4^{b}$ & $31.7 \pm 7.6^{b}$ \\
\hline Methyl hexanoate & $23.9 \pm 1.3^{\mathrm{a}}$ & $-b$ & $-b$ & $3.6 \pm 6.3^{\mathrm{a}}$ & $2.8 \pm 4.8^{\mathrm{a}}$ & $9.6 \pm 8.3^{\mathrm{a}}$ \\
\hline 2 or 3-Methyl-1-butanol & $322.9 \pm 8.5^{a}$ & $367.6 \pm 28.1^{a}$ & $298.7 \pm 22.8^{a}$ & $198.4 \pm 36.2^{b}$ & $213.2 \pm 42.2^{b}$ & $205.0 \pm 21.5^{b}$ \\
\hline Acetoin & $-b$ & $-b$ & $-b$ & $-b$ & $2.6 \pm 4.6^{\mathrm{a}}$ & $-b$ \\
\hline Acetic acid & $-b$ & $-b$ & $-b$ & $21.9 \pm 5.7^{\mathrm{a}}$ & $22.1 \pm 3.0^{\mathrm{a}}$ & $17.7 \pm 2.0^{\mathrm{a}}$ \\
\hline
\end{tabular}

${ }^{\dagger}$ Concentration refers to the internal standard (cyclohexanone $3.6 \mu \mathrm{g} / \mathrm{mL}$ ), to which a value of 100 was given; $\ddagger 2,2,4,6,6$ Pentamethyl heptane; - Not detected; different superscript letters indicate mean differences among strains, for each compound $(p<0.05)$.

\subsubsection{Production of Antimicrobial Substances}

Under the present test conditions, none of the strains produced antimicrobials that inhibited the growth of the indicator strains shown in Table 1.

\subsection{Safety of GABA-Producing L. lactis Strains}

\subsubsection{Biogenic Amine Production}

None of the six GABA-producing strains produced tyramine, histamine, or cadaverine (Table 5) nor were any corresponding gene clusters found in any of their genomes. However, all the isolates produced putrescine via the agmatine deiminase route (AGDI), but not through the ODC pathway (Table 5). No significant differences were seen among the mean concentrations of putrescine produced by the six strains $(p<0.05)$.

As expected, the AGDI gene cluster involved in putrescine production in L. lactis, which is composed of $a g u R$ (a positive regulatory gene) followed by the aguBDAC operon (encoding the catabolic enzymes for the decarboxylation of agmatine to putrescine and the agmatine/putrescine antiporter gene) [38], was identified in all the strains (Table S2). 
Table 5. Biogenic amine production ( $\mathrm{mM}$; mean \pm standard deviation) in cultures of L. lactis isolates.

\begin{tabular}{cccccc}
\hline L. lactis Isolates & Tyramine & Histamine & $\begin{array}{c}\text { Putrescine } \\
\text { (AGDI }^{\mathbf{1}} \text { ) }\end{array}$ & $\begin{array}{c}\text { Putrescine } \\
\text { (ODC }^{2} \text { ) }\end{array}$ & Cadaverine \\
\hline LEY6 & - & - & $0.785 \pm 0.02^{\mathrm{a}}$ & - & - \\
LEY7 & - & - & $0.758 \pm 0.02^{\mathrm{a}}$ & - & - \\
LEY8 & - & - & $0.763 \pm 0.02^{\mathrm{a}}$ & - & - \\
LEY11 & - & - & $0.791 \pm 0.02^{\mathrm{a}}$ & - & - \\
LEY12 & - & - & $0.776 \pm 0.01^{\mathrm{a}}$ & - & - \\
LEY13 & - & - & $0.803 \pm 0.01^{\mathrm{a}}$ & - & - \\
\hline
\end{tabular}

${ }^{1}$ AGDI: agmatine deiminase route; ${ }^{2}$ ODC: ornithine decarboxylase route; - BA production not detected; ${ }^{\text {a }}$ same superscript letter indicates no significant differences among groups $(p<0.05)$.

\subsubsection{Antimicrobial Resistance Genes}

Neither the RGI nor ResFinder analysis detected any antimicrobial resistance genes in any of the six GABA-producing L. lactis genomes.

\subsection{All Six L. lactis Strains Produced GABA in a Cabrales-Like Mini Cheese Model; None Produced BA}

All six tested L. lactis strains were able to accumulate GABA at concentrations ranging from $350 \mathrm{mg} / \mathrm{kg}$ (LEY6) to $457 \mathrm{mg} / \mathrm{kg}$ (LEY12) (Figure 4a) (no significant difference).

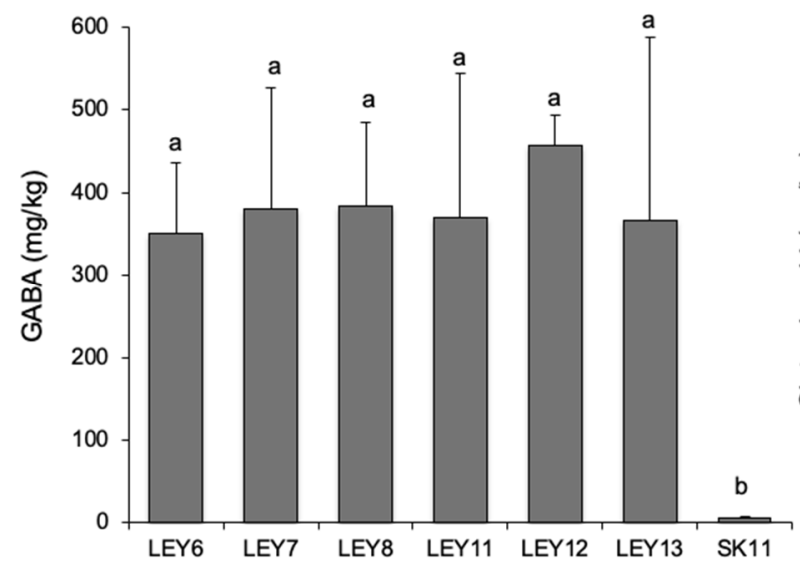

(a)

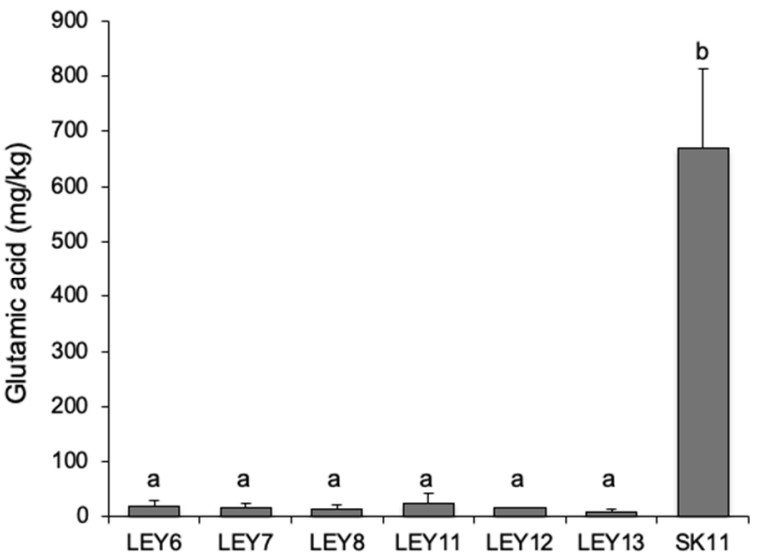

(b)

Figure 4. (a) GABA and (b) glutamic acid accumulation $(\mathrm{mg} / \mathrm{kg})$ in Cabrales-like experimental cheeses made using the $L$. lactis strains individually as starter cultures. Bars with different letters indicate significant differences in GABA or glutamic acid accumulation $(p<0.05)$ compared to control cheeses made with the non-GABA producing strain L. lactis SK11.

As expected, significant differences in GABA production were recorded $(p<0.05)$ compared to the control strain L. lactis SK11, which produced near-negligible amounts. Apart from the glutamic acid they used in protein biosynthesis, the GABA-producing $L$. lactis strains completely transformed the glutamic acid appearing as a consequence of casein proteolysis into GABA (Figure $4 \mathrm{~b}$ ). In contrast, a mean glutamic acid concentration of about $670 \mathrm{mg} / \mathrm{kg}$ remained in the cheeses made with the non-GABA producing L. lactis SK11 strain (Figure $4 b$ ). None of the cheeses made with any of the six GABA-producing $L$. lactis strains, or L. lactis SK11, accumulated any of the BA analyzed, not even putrescine.

\section{Discussion}

GABA, a compound with beneficial effects on human health, is naturally present in many varieties of cheese, although the extent of its accumulation depends on multiple environmental, technological, and metabolic factors [39]. There is much interest in developing functional cheeses with high GABA contents, and the use of GABA-producing L. lactis strains with good technological characteristics as starter cultures deserves investigation. 
In the present work, six L. lactis subsp. lactis strains that produced GABA in GM17 broth supplemented with monosodium glutamate (Figure 1) were isolated from raw camel's milk. To our knowledge, this is the first report of the isolation of GABA-producing L. lactis strains from milk. Some have been isolated from fermented dairy products such as yogurt [40] and cheese [41-44], but none has been isolated from the raw milk of any mammal, which has been the dairy source chosen in this work to look for GABA-producing lactococci. The amounts of GABA produced by these L. lactis strains ranged from $1.21 \mathrm{mM}$ for LEY13, to $1.80 \mathrm{mM}$ for LEY7, i.e., in the mid-high range reported for these other L. lactis strains isolated from other dairy sources than milk $[40,42,44]$.

The technological behavior of the strains agreed with their possession of genomic elements involved in their adaptation to the dairy environment, such as the lactose utilization operon (lacR-ABCDFEGX), the proteolytic system (prtP-prtM), and the oligopeptide permease system (oppDFBCA) (Table S2). Indeed, all six GABA-producing strains showed high acidification rates in milk, the capacity to clot milk (Table 3), and good proteolytic activity (Figure 3). While the acid-producing capacity of a starter is important for milk coagulation, it can also help prevent the growth of spoilage microorganisms and pathogens, and a good proteolytic system contributes to the release of oligopeptides and amino acids during ripening. The catabolism of the volatile compounds produced assists in the development of the final organoleptic characteristics of the fermented product. All six GABA-producing L. lactis strains produced different volatile compounds after $24 \mathrm{~h}$ of growth in milk (Table 4 ). Thus, all six showed good technological traits, suggesting they might be of use as functional starter cultures for the production of GABA-enriched fermented dairy products.

In silico analysis of the strains' genomes revealed the absence of any antimicrobial resistance gene or gene cluster involved in the biosynthesis of tyramine, histamine, putrescine through the ODC pathway, or cadaverine. However, all possessed genes responsible for the production of putrescine from agmatine via the AGDI pathway; this is considered a specific trait of L. lactis, although many dairy strains have lost it [38]. Although all six strains produced putrescine in culture media supplemented with agmatine (Table 5), neither putrescine nor any other BA was accumulated in any of the experimental cheeses. The absence of agmatine-producing microorganisms in the cheese microbiota would explain why putrescine did not accumulate. In fact, no agmatine production was detected in the control cheeses. However, it cannot be ruled out that GABA-producing L. lactis strains would not synthesize putrescine in cheeses that do contain agmatine-producing microorganisms; this needs to be further explored. In this respect, it is worth noting that the elimination of the genes involved in the production of putrescine in E. faecalis has no effect on its fitness or the expression of other genes [45].

The only discrepancy between the genomic data and the experimental results was the presence of different bacteriocin-producing loci in the genomes of the L. lactis strains but a lack of inhibitory activity against the indicator strains tested. However, it should be remembered that in silico predictions cannot guarantee that loci are complete and functional. In addition, bacteriocin production in LAB is a highly regulated process involving several factors, and certainly, bacteriocins are produced only under appropriate conditions [46]. Moreover, even though the L. lactis strains might have had the capacity to produce bacteriocins, the indicator strains selected might not have been sensitive to them. More work is needed to determine the functionality of the bacteriocin loci identified, the conditions for the production of bacteriocins, and their antibacterial spectrum.

From a technological viewpoint, the most interesting result is that the use of all six GABA-producing L. lactis strains as starters led to the accumulation of GABA in the experimental cheeses. The mean GABA concentration of the six cheeses was $384 \mathrm{mg} / \mathrm{kg}$, while the concentration of the cheese made with LEY12 reached $457 \mathrm{mg} / \mathrm{kg}$. There are very few reports on the production of GABA-rich cheeses made with GABA-producing $L$. lactis starter cultures. One describes the use of L. lactis subsp. lactis biovar diacetylactis 01-7 (approximate inoculum size $2.7 \times 10^{8} \mathrm{cfu}$ per $\mathrm{mL}$ of pasteurized milk), which is a strain isolated from a cheese starter [17]. However, the mean GABA accumulation was lower 
$(1722 \mathrm{nmol} / \mathrm{g}[178 \mathrm{mg} / \mathrm{kg}])$ than that achieved in the present work. Another study reports the production of Saint-Paulin experimental cheeses with high concentrations of GABA (from 407-1979 mg/kg) [18] using the same 01-7 strain mentioned above and L. lactis subsp. lactis biovar diacetylactis $01-1$ as starter cultures. GABA accumulation in some of those cheeses was about 4.5 times that of the greatest achieved in the present study $(457 \mathrm{mg} / \mathrm{kg}$ in cheeses made with LEY12). However, it should be noted that in this earlier work, the cheeses were supplemented with monosodium glutamate $(0.3 \% w / w$ fresh cheese), which is a substrate for GABA biosynthesis. Similarly, high concentrations of GABA (up to $766 \mathrm{mg} / \mathrm{kg}$ ) were reported to accumulate in slurries simulating the composition of Cheddar cheese when supplemented with $3 \mathrm{mg} / \mathrm{g}$ of glutamate and inoculated with GABA-producing L. lactis subsp. lactis ULAAC-H13 and L. lactis subsp. lactis ULAAC-A23 (isolated from an old-style cheese starter) [47]. The cheeses made in the present study were not similarly supplemented; all the GABA accumulated was synthesized from the glutamate released by casein proteolysis (which was totally consumed and is therefore a limiting factor in GABA production). Taking into account the amount of GABA produced and the tendency of consumers to reject food additives, the six L. lactis strains isolated in the present work could be a good technological option. Similar studies by Nomura et al. [18] and Pouliot-Mathieu et al. [12] describe the production of GABA-enriched Cheddar cheeses with no added glutamate but using other L. lactis starters. The proteolytic activity of these, added to that of the lactobacilli present in the cheese microbiota, would release this amino acid. In the present work, the GABA-producing L. lactis strains were the only starters added, but the Cabrales cheese model used also carries the proteolytic mold P. roqueforti, which would have likely caused the appearance of available glutamate.

The parameters used for cheese production in the present work were those routinely used in making Cabrales cheese, but they might be optimized for GABA accumulation. A study by Gardner-Fortier et al. [47] determined the optimal glutamate, $\mathrm{pH}$, and saltto-moisture ratio conditions for GABA production by L. lactis subsp. lactis in ripening Cheddar cheese. GABA accumulation increased with the concentration of glutamate and with the lowest salt-to-moisture ratio tested (3\%), but the critical factor was a $\mathrm{pH}$ of 4.8; at $\mathrm{pH} 5.1$ or $\mathrm{pH} 5.4$, GABA production was very poor. These results might be expected since chloride, glutamate, and low $\mathrm{pH}$ are known to regulate the expression of the GAD operon in L. lactis, and therefore the biosynthesis of GABA $[19,21]$. Moreover, the activity of glutamate decarboxylase is enhanced by glutamate and low $\mathrm{pH}$ (below 5.0) [18]; the presence of other compounds such as arginine and malate also improve GABA production [48]. Together, these findings suggest that GABA accumulation in cheeses can be increased via the optimization of different technological parameters and the use of starter cultures made by combining the L. lactis strains presented in this study with others of technological interest.

GABA-enriched cheeses made using the six investigated strains might be expected to provide health benefits. Inoue et al. [9] showed that a daily intake of 10-12 mg of GABA over 12 weeks via GABA-enriched fermented milk reduced blood pressure in human subjects with mild hypertension. The same was observed when mildly hypertensive men consumed GABA-enriched Cheddar cheese daily (16 mg GABA per day for 12 weeks) [12]. Taking the mean GABA accumulation of $384 \mathrm{mg} / \mathrm{kg}$ recorded in the present work, a daily portion of $50 \mathrm{~g}$ of cheese (which would provide about $19 \mathrm{mg}$ of GABA) would be enough to have positive effects on human blood pressure; for cheeses accumulating the maximum recorded $(457 \mathrm{mg} / \mathrm{kg}), 23 \mathrm{mg}$ of GABA would be available.

\section{Conclusions}

This work reports the isolation of six GABA-producing L. lactis subsp. lactis strains from raw camel's milk collected in Algeria. Genome sequencing revealed all to possess the GAD gene cluster responsible for GABA production, plus genes involved in adaptation to the dairy environment. In addition to showing good technological and safety characteristics, these strains, when used individually as starter cultures, produced experimental Cabrales- 
like mini cheeses with high GABA concentrations. Therefore, raw Algerian camel's milk would appear to be an excellent source of GABA-producing L. lactis strains with good technological and safety characteristics, which could be used as functional starter cultures for the production of GABA-enriched cheeses beneficial to consumers' health.

Supplementary Materials: The following are available online at https:/ /www.mdpi.com/2304-8 158/10/3/633/s1, Table S1: Genome features of the GABA-producing L. lactis isolates; Table S2: Annotation and localization (locus_tag) of the main features related to technological, functional and safety properties in the genomes of the GABA-producing L. lactis isolates.

Author Contributions: Conceptualization, M.A.A.; data curation, B.R.; funding acquisition, M.A.A.; methodology, B.R., Y.S., L.S., V.L. and B.d.R.; supervision, M.A.A.; writing—original draft, B.d.R.; writing-review and editing, B.R., V.L., B.d.R. and M.A.A. All authors have read and agreed to the published version of the manuscript.

Funding: This work was funded by the Spanish State Research Agency (AEI) and the European Regional Development Funds (FEDER) (AGL2016-78708-R, AEI/FEDER, UE); by the Plan for Science, Technology and Innovation of the Principality of Asturias 2018-2020, co-financed by FEDER (IDI/2018/000114, FICYT/FEDER, UE); and by the Spanish National Research Council (CSIC201870I091, CSIC).

Data Availability Statement: Data is contained within the article or supplementary material. The genome sequences of GABA-producing L. lactis strains are openly available in the NCBI BioProject database (BioProject PRJNA596610; http:/ / www.ncbi.nlm.nih.gov/bioproject/596610, accessed on 27 January 2021) under the accession numbers SAMN13634154, SAMN13634584, SAMN13634590, SAMN13634615, SAMN13634616, and SAMN13634617.

Acknowledgments: The authors acknowledge support of the publication fee by the CSIC Open Access Publication Support Initiative through its Unit of Information Resources for Research (URICI) and thank Adrian Burton for language and editing assistance.

Conflicts of Interest: None to declare. The funders had no role in the design of this study, in the collection, analysis or interpretation of data, in the writing of the manuscript, or in the decision to publish the results.

\section{References}

1. Koutsoumanis, K.; Allende, A.; Álvarez-Ordóñez, A.; Bolton, D.; Bover-Cid, S.; Chemaly, M.; Davies, R.; Hilbert, F.; Lindqvist, R.; Nauta, M.; et al. Update of the list of QPS-recommended biological agents intentionally added to food or feed as notified to EFSA 9: Suitability of taxonomic units notified to EFSA until september 2018. EFSA J. 2019, 17. [CrossRef]

2. FDA Gamma-Aminobutyric Acid GRAS. Notice Number 595. 2015. Available online: https:/ /www.fda.gov/food/gras-noticeinventory / agency-response-letter-gras-notice-no-grn-000595 (accessed on 27 January 2021).

3. Smit, G.; Smit, B.A.; Engels, W.J.M. Flavour formation by lactic acid bacteria and biochemical flavour profiling of cheese products. FEMS Microbiol. Rev. 2005, 29, 591-610. [CrossRef]

4. Ayad, E.H.E.; Verheul, A.; Wouters, J.T.M.; Smit, G. Antimicrobial-producing wild lactococci isolated from artisanal and non-dairy origins. Int. Dairy J. 2002, 12, 145-150. [CrossRef]

5. Nishitani, Y.; Tanoue, T.; Yamada, K.; Ishida, T.; Yoshida, M.; Azuma, T.; Mizuno, M. Lactococcus lactis subsp. cremoris FC alleviates symptoms of colitis induced by dextran sulfate sodium in mice. Int. Immunopharmacol. 2009, 9, 1444-1451. [CrossRef] [PubMed]

6. $\quad$ Luerce, T.D.; Gomes-Santos, A.C.; Rocha, C.S.; Moreira, T.G.; Cruz, D.N.; Lemos, L.; Sousa, A.L.; Pereira, V.B.; De Azevedo, M.; Moraes, K.; et al. Anti-inflammatory effects of Lactococcus lactis NCDO 2118 during the remission period of chemically induced colitis. Gut Pathog. 2014, 6, 33. [CrossRef]

7. Ramalho, J.B.; Soares, M.B.; Spiazzi, C.C.; Bicca, D.F.; Soares, V.M.; Pereira, J.G.; Da Silva, W.P.; Sehn, C.P.; Cibin, F.W.S. In vitro probiotic and antioxidant potential of Lactococcus lactis subsp. cremoris 1195 and its effect in mice behaviour. Nutrients 2019, 11, 901. [CrossRef]

8. Diez-Gutiérrez, L.; San Vicente, L.; Barrón, L.J.R.; Villarán, M.D.C.; Chávarri, M. Gamma-aminobutyric acid and probiotics: Multiple health benefits and their future in the global functional food and nutraceuticals market. J. Funct. Foods 2020, 64, 103669. [CrossRef]

9. Inoue, K.; Shirai, T.; Ochiai, H.; Kasao, M.; Hayakawa, K.; Kimura, M.; Sansawa, H. Blood-pressure-lowering effect of a novel fermented milk containing $\gamma$-aminobutyric acid (GABA) in mild hypertensives. Eur. J. Clin. Nutr. 2003, 57, 490-495. [CrossRef]

10. Chen, L.; Zhao, H.; Zhang, C.; Lu, Y.; Zhu, X.; Lu, Z. $\gamma$-Aminobutyric acid-rich yogurt fermented by Streptococcus salivarius subsp. thermophiles fmb5 appears to have anti-diabetic effect on streptozotocin-induced diabetic mice. J. Funct. Foods. 2016, 20, 267-275. [CrossRef] 
11. Renes, E.; Ladero, V.; Tornadijo, M.E.; Fresno, J.M. Production of sheep milk cheese with high $\gamma$-aminobutyric acid and ornithine concentration and with reduced biogenic amines level using autochthonous lactic acid bacteria strains. Food Microbiol. 2019, 78, 1-10. [CrossRef]

12. Pouliot-Mathieu, K.; Gardner-Fortier, C.; Lemieux, S.; St-Gelais, D.; Champagne, C.P.; Vuillemard, J.C. Effect of cheese containing gamma-aminobutyric acid-producing lactic acid bacteria on blood pressure in men. Pharma Nutrition 2013, 1, 141-148. [CrossRef]

13. Carafa, I.; Stocco, G.; Nardin, T.; Larcher, R.; Bittante, G.; Tuohy, K.; Franciosi, E. Production of naturally $\gamma$-aminobutyric acid-enriched cheese using the dairy strains Streptococcus thermophilus 84C and Lactobacillus brevis DSM 32386. Front. Microbiol. 2019, 10, 93. [CrossRef]

14. Wang, H.K.; Dong, C.; Chen, Y.F.; Cui, L.M.; Zhang, H.P. A new probiotic Cheddar cheese with high ACE-inhibitory activity and $\gamma$-aminobutyric acid content produced with koumiss-derived Lactobacillus casei Zhang. Food Technol. Biotechnol. 2010, 48, 62-70.

15. Irigoyen, A.; Ortigosa, M.; Juansaras, I.; Oneca, M.; Torre, P. Influence of an adjunct culture of Lactobacillus on the free amino acids and volatile compounds in a Roncal-type ewe's-milk cheese. Food Chem. 2007, 100, 71-80. [CrossRef]

16. Fröhlich-Wyder, M.T.; Bisig, W.; Guggisberg, D.; Irmler, S.; Jakob, E.; Wechsler, D. Influence of low pH on the metabolic activity of Lactobacillus buchneri and Lactobacillus parabuchneri strains in Tilsit-type model cheese. Dairy Sci. Technol. 2015, 95, 569-585. [CrossRef]

17. Hagi, T.; Nakagawa, H.; Ohmori, H.; Sasaki, K.; Kobayashi, M.; Narita, T.; Nomura, M. Characterization of unique metabolites in $\gamma$-aminobutyric acid-rich cheese by metabolome analysis using liquid chromatography-mass spectrometry. J. Food Biochem. 2019, 43, e13039. [CrossRef] [PubMed]

18. Nomura, M.; Kimoto, H.; Someya, Y.; Furukawa, S.; Suzuki, I. Production of $\gamma$-aminobutyric acid by cheese starters during cheese ripening. J. Dairy Sci. 1998, 81, 1486-1491. [CrossRef]

19. Sanders, J.W.; Leenhouts, K.; Burghoorn, J.; Brands, J.R.; Venema, G.; Kok, J. A chloride-inducible acid resistance mechanism in Lactococcus lactis and its regulation. Mol. Microbiol. 1998, 27, 299-310. [CrossRef] [PubMed]

20. Su, M.S.; Schlicht, S.; Gänzle, M.G. Contribution of glutamate decarboxylase in Lactobacillus reuteri to acid resistance and persistence in sourdough fermentation. Microb. Cell Fact. 2011, 10. [CrossRef]

21. Cotter, P.D.; Hill, C. Surviving the Acid Test: Responses of Gram-Positive Bacteria to Low pH. Microbiol. Mol. Biol. Rev. 2003, 67, 429-453. [CrossRef]

22. Limon, A.; Gallegos-Perez, J.L.; Reyes-Ruiz, J.M.; Aljohi, M.A.; Alshanqeeti, A.S.; Miledi, R. The endogenous GABA bioactivity of camel, bovine, goat and human milks. Food Chem. 2014, 145, 481-487. [CrossRef]

23. Gasson, M.J. Plasmid complements of Streptococcus lactis NCDO 712 and other lactic streptococci after protoplast-induced curing. J. Bacteriol. 1983, 154, 1-9. [CrossRef] [PubMed]

24. Visser, S.; Exterkate, F.A.; Slangen, C.J.; de Veer, G.J. Comparative study of action of cell wall proteinases from various strains of Streptococcus cremoris on bovine alpha(s1)-, beta-, and kappa-casein. Appl. Environ. Microbiol. 1986, 52, 1162-1166. [CrossRef] [PubMed]

25. del Rio, B.; Redruello, B.; Ladero, V.; Fernandez, M.; Martin, M.C.; Alvarez, M.A. Putrescine production by Lactococcus lactis subsp. cremoris CECT 8666 is reduced by $\mathrm{NaCl}$ via a decrease in bacterial growth and the repression of the genes involved in putrescine production. Int. J. Food Microbiol. 2016, 232, 1-6. [CrossRef] [PubMed]

26. Axelsson, L.; Ahrné, S. Lactic Acid Bacteria. In Applied Microbial Systematics; Priest, F.G., Goodfellow, M., Eds.; Springer: Dordrecht, The Netherlands, 2000; pp. 367-388. ISBN 978-94-011-4020-1.

27. Marroki, A.; Zúñiga, M.; Kihal, M.; Pérez-Martínez, G. Characterization of Lactobacillus from algerian goat's milk based on phenotypic, 16S rDNA sequencing and their technological properties. Braz. J. Microbiol. 2011, 42, 158-171. [CrossRef]

28. Drici, H.; Gilbert, C.; Kihal, M.; Atlan, D. A typical citrate-fermenting Lactococcus lactis strains isolated from dromedary's milk. J. Appl. Microbiol. 2010, 108, 647-657. [CrossRef]

29. Saidi, Y.; del Rio, B.; Senouci, D.E.; Redruello, B.; Martinez, B.; Ladero, V.; Kihal, M.; Alvarez, M.A. Polyphasic characterisation of non-starter lactic acid bacteria from Algerian raw Camel's milk and their technological aptitudes. Food Technol. Biotechnol. 2020, 58, 260-272. [CrossRef] [PubMed]

30. Redruello, B.; Ladero, V.; Cuesta, I.; Álvarez-Buylla, J.R.; Martín, M.C.; Fernández, M.; Alvarez, M.A. A fast, reliable, ultra high performance liquid chromatography method for the simultaneous determination of amino acids, biogenic amines and ammonium ions in cheese, using diethyl ethoxymethylenemalonate as a derivatising agent. Food Chem. 2013, 139, 1029-1035. [CrossRef]

31. Tatusova, T.; Dicuccio, M.; Badretdin, A.; Chetvernin, V.; Nawrocki, E.P.; Zaslavsky, L.; Lomsadze, A.; Pruitt, K.D.; Borodovsky, M.; Ostell, J. NCBI prokaryotic genome annotation pipeline. Nucleic Acids Res. 2016, 44, 6614-6624. [CrossRef]

32. Altschul, S. Basic Local Alignment Search Tool. J. Mol. Biol. 1990, 215, 403-410. [CrossRef]

33. Van Heel, A.J.; De Jong, A.; Song, C.; Viel, J.H.; Kok, J.; Kuipers, O.P. BAGEL4: A user-friendly web server to thoroughly mine RiPPs and bacteriocins. Nucleic Acids Res. 2018, 46, W278-W281. [CrossRef]

34. Page, A.J.; Cummins, C.A.; Hunt, M.; Wong, V.K.; Reuter, S.; Holden, M.T.G.; Fookes, M.; Falush, D.; Keane, J.A.; Parkhill, J. Roary: Rapid large-scale prokaryote pan genome analysis. Bioinformatics 2015, 31, 3691-3693. [CrossRef]

35. Hadfield, J.; Croucher, N.J.; Goater, R.J.; Abudahab, K.; Aanensen, D.M.; Harris, S.R. Phandango: An interactive viewer for bacterial population genomics. Bioinformatics 2018, 34, 292-293. [CrossRef] [PubMed]

36. Zankari, E.; Hasman, H.; Cosentino, S.; Vestergaard, M.; Rasmussen, S.; Lund, O.; Aarestrup, F.M.; Larsen, M.V. Identification of acquired antimicrobial resistance genes. J. Antimicrob. Chemother. 2012, 67, 2640-2644. [CrossRef] [PubMed] 
37. Alcock, B.P.; Raphenya, A.R.; Lau, T.T.Y.; Tsang, K.K.; Bouchard, M.; Edalatmand, A.; Huynh, W.; Nguyen, A.L.V.; Cheng, A.A.; Liu, S.; et al. CARD 2020: Antibiotic resistome surveillance with the comprehensive antibiotic resistance database. Nucleic Acids Res. 2020, 48, D517-D525. [CrossRef] [PubMed]

38. Ladero, V.; Rattray, F.P.; Mayo, B.; Martín, M.C.; Fernández, M.; Alvarez, M.A. Sequencing and Transcriptional Analysis of the Biosynthesis Gene Cluster of Putrescine-Producing Lactococcus lactis. Appl. Environ. Microbiol. 2011, 77, 6409-6418. [CrossRef]

39. Redruello, B.; Szwengiel, A.; Ladero, V.; del Rio, B.; Alvarez, M.A. Identification of technological/metabolic/environmental profiles of cheeses with high GABA contents. LWT Food Sci. Technol. 2020, 130, 109603. [CrossRef]

40. Lu, X.; Chen, Z.; Gu, Z.; Han, Y. Isolation of $\gamma$-aminobutyric acid-producing bacteria and optimization of fermentative medium. Biochem. Eng. J. 2008, 41, 48-52. [CrossRef]

41. Diana, M.; Tres, A.; Quílez, J.; Llombart, M.; Rafecas, M. Spanish cheese screening and selection of lactic acid bacteria with high gamma-aminobutyric acid production. LWT Food Sci. Technol. 2014, 56, 351-355. [CrossRef]

42. Franciosi, E.; Carafa, I.; Nardin, T.; Schiavon, S.; Poznanski, E.; Cavazza, A.; Larcher, R.; Tuohy, K.M. Biodiversity and $\gamma$ -aminobutyric acid production by lactic acid bacteria isolated from traditional alpine raw cow's milk cheeses. Biomed. Res. Int. 2015, 2015, 625740. [CrossRef] [PubMed]

43. Siragusa, S.; De Angelis, M.; Di Cagno, R.; Rizzello, C.G.; Coda, R.; Gobbetti, M. Synthesis of $\gamma$-aminobutyric acid by lactic acid bacteria isolated from a variety of Italian cheeses. Appl. Environ. Microbiol. 2007, 73, 7283-7290. [CrossRef] [PubMed]

44. Valenzuela, J.A.; Flórez, A.B.; Vázquez, L.; Vasek, O.M.; Mayo, B. Production of $\gamma$-aminobutyric acid (GABA) by lactic acid bacteria strains isolated from traditional, starter-free dairy products made of raw milk. Benef. Microbes. 2019, 10, 579-587. [CrossRef]

45. Perez, M.; Calles-Enríquez, M.; del Rio, B.; Redruello, B.; de Jong, A.; Kuipers, O.P.; Kok, J.; Martin, M.C.; Ladero, V.; Fernandez, M.; et al. Construction and characterization of a double mutant of Enterococcus faecalis that does not produce biogenic amines. Sci. Rep. 2019, 9, 16881. [CrossRef]

46. Maldonado-Barragán, A.; Ruiz-Barba, J.L.; Jiménez-Díaz, R. Knockout of three-component regulatory systems reveals that the apparently constitutive plantaricin-production phenotype shown by Lactobacillus plantarum on solid medium is regulated via quorum sensing. Int. J. Food Microbiol. 2009, 130, 35-42. [CrossRef] [PubMed]

47. Gardner-Fortier, C.; St-Gelais, D.; Champagne, C.P.; Vuillemard, J.C. Determination of optimal conditions for $\gamma$-aminobutyric acid production by Lactococcus lactis ssp. lactis. Int. Dairy J. 2013, 32, 136-143. [CrossRef]

48. Laroute, V.; Yasaro, C.; Narin, W.; Mazzoli, R.; Pessione, E.; Cocaign-Bousquet, M.; Loubière, P. GABA production in Lactococcus lactis is enhanced by Arginine and co-addition of malate. Front. Microbiol. 2016, 7, 1050. [CrossRef] [PubMed] 